Primož Potočnik, Edvard Govekar

Adaptive Optimization of Heating Curves in Buildings Heated by a Weather-Compensated Heat Pump

Science and Technology for the Built Environment (2019).

(Accepted author version posted online: 10 May 2019, Published online: 18 Jun 2019)

(C) 2019. This manuscript version is made available under the CC-BY-NC-ND 4.0 license

http://creativecommons.org/licenses/by-nc-nd/4.0/

Link to published article: https://www.tandfonline.com/doi/full/10.1080/237444731.2019.1616984

DOI: https://doi.org/10.1080/23744731.2019.1616984

\title{
Adaptive Optimization of Heating Curves in Buildings Heated by a Weather- Compensated Heat Pump
}

Primož Potočnik* and Edvard Govekar

University of Ljubljana, Faculty of Mechanical Engineering, Ljubljana, Slovenia

This paper is concerned with the weather compensated heating of buildings by means of air-towater heat pumps. A novel adaptive method is proposed for on-line optimization of the heating curve which defines the relation between the heating temperature and the outdoor temperature. Parametrization of the linear heating curve with two reference points is presented, with the aim of providing good tracking of the desired indoor temperature by adaptively adjusting the reference points of the heating curve. Two adaptation strategies are investigated, and a wide range of adaptation constants is explored. The use of these methods is demonstrated on two different buildings, simulated in TRNSYS. The simulation model was validated on a reference building. The results of adaptive optimization show very good performance which is comparable to and even better than the performance based on referential optimal static heating curves.

Keywords: buildings space heating, heating curve optimization, adaptive control, weathercompensated temperature

\section{Introduction}

With the implementation of new energy efficiency guidelines in the building sector (Zygierewicz 2016) emphasizing the need to reduce final energy consumption, the wider use of heat pumps is an energy and cost-efficient way forwards to the achievement of a low carbon society. A decrease in energy consumption could, on the one hand, be achieved by increasing the thermal efficiency of the building envelope, and, on the other hand, by applying advanced process control techniques to building services. EHPA (the European Heat Pump Association) has predicted a rapid market growth over this decade, and as a result ever more intensive research and development activities can be observed in this domain, including research into environmentally-friendly and energy-efficient refrigerants (McLinden et al. 2017; Sagia and Rakopoulos 2016), improvements in the energy efficiency of vapour-compression cycles and heat transfer (Chua, Chou, and Yang 2010; Song et al. 2018; Willem, Lin, and Lekov 2017; Park et al. 2015), research into alternative technologies to vapour compression (William Goetzler, Robert Zogg, Jim Young 2014), investigation into various energy 
sources for monovalent and bivalent operation (Mohanraj et al. 2018; Poppi et al. 2018; Hedegaard et al. 2012), integration into smart grids (Fischer and Madani 2017; Kreuder and Spataru 2015; Carvalho et al. 2015), and finally, smart control, system integration and operation (Madani, Claesson, and Lundqvist 2011; Kandler, Wimmer, and Honold 2015; Thieblemont et al. 2017). Recently many smart algorithms have been developed, focusing on various aspects, such as human occupancy and behaviour (D’Oca, Hong, and Langevin 2018; Balvedi, Ghisi, and Lamberts 2018), weather influences (Kwak and Huh 2016), building dynamics and the predictive control of heat pumps (van Leeuwen et al. 2016; Zhuang, Chen, and Chen 2018; Afram et al. 2017), operational-cost efficiency (Candanedo and Dehkordi 2014; Kajgaard et al. s2013), forecasting and optimization (Meng et al. 2018), and improved thermal comfort. Apart from energy efficiency, the latter has become a very important factor in the design of modern smart buildings. The study presented by (de Wilde and Tian 2010) demonstrated also the importance of the implementation of adaptive thermal comfort models, and of their possible applications in climate change impact studies, and in building design, in order to make buildings more resilient towards change.

Considerable improvements in thermal comfort can be achieved by using advanced process control techniques, such as model predictive control (MPC) (Serale et al. 2018; Lindelöf et al. 2015), where the optimization system consists of a thermal model of the building, weather forecasts, various constraints, and an optimization algorithm. The benefits of applying MPC to building services have been broadly investigated in a number of studies (Smarra et al. 2018; Schmelas, Feldmann, and Bollin 2017). Although good results have been reported when using a rather simple first order house model for the MPC of a domestic heat pump (Kajgaard et al. 2013), for the effective operation of MPC it is the precision and accuracy of the thermal building models which is the most important (Prívara et al. 2013). There are three general categories of thermal building models: detailed physical models or so called white-box models, simplified physical or grey-box models, and statistically-based models (Li and Wen 2014). In many of today's building model predictive applications, smart on-line optimization is not yet fully available due to the high complexity of the system, or due to the associated costs. For this reason simple and cost-efficient solutions need to be developed in order to gain access to broader applications in modern buildings, such as the simplified self-learning predictive control approach (Thieblemont et al. 2018).

Alternative simplified and cost-efficient approaches involve the possibilities of weather compensation by the adaptation or optimization of the weather-controlled heating curves. A recent investigation has demonstrated the possibilities for the low-cost improvement in thermal comfort by the generalization and optimization of heating curves (Potočnik et al. 2018). The proposed approach appears to be a promising and simple alternative to predictive control approaches. A few studies investigated adaptation of the heat curve, and most of them were concerned with adaptation to different desired room temperatures, as presented in (Saloky and Pitel 2005). An example of a commercial weather compensation controller has been provided by Vaillant (Vaillant 2012). Their model analyses the variations in room temperature, and adapting the heat curve by performing a parallel shift when the desired room temperature is changed. A study of an adaptive heat curve for the automatic optimization of district heating installations was presented by (Ionesi et al. 2015). It demonstrated that the implementation of a building specific heat curve increases the thermal comfort in the building by adjusting the room temperature so that it is in $\mathrm{a} \pm 0.5^{\circ} \mathrm{C}$ range around the desired temperature, and reduces the energy consumption by $5 \%$, compared to a baseline study. The influence of the supply temperature on the seasonal performance factor of heating systems was examined by varying the heating curve in (Huchtemann and Müller 2013). An air-to-water heat pump system for the heating of a one-family home was numerically analysed, and an adaptive control 
algorithm was studied which lowers the supply temperature according to the actual heating demand. The results demonstrated an increase in the seasonal performance factor of up to 0.19 , and savings in annual primary energy demand compared to a standard controlling of up to $6.8 \%$.

In this paper, a simple yet efficient novel adaptive algorithm is proposed for the online adaptation of heating curves. The method is based on the parametrization of the heating curve by two reference points, defining the linear relation between the heating temperature $T_{\text {heat }}$ (denoting water supply temperature) and the outdoor temperature $T_{\text {out }}$. A method for the adaptive optimization of the defined heating curve is proposed with the aim of tracking the desired indoor temperature $T_{\text {in SET by }}$ adjusting the heating curve. Two adaptation strategies are investigated, and a wide range of adaptation constants is explored. The method is demonstrated on two different buildings, simulated in TRNSYS, and the results show very good performance comparable to and even better than the performance based on referential optimal static heating curves. The benefits gained by using the proposed method include good tracking of the desired indoor temperature, which results in increased thermal comfort, and also energy savings due to heat pump operation at lower heating temperatures, which in turn increases the heat pump's COP (coefficient of performance).

The paper is made up of the following parts: Simulation data for two different buildings and weather data are introduced in Section 2. Section 3 describes methods including the parametrization of heating curves, and the proposed approach for the adaptive optimization of heating curves, based on two different adaptation strategies. The results of the various simulations are presented in Section 4 , where the initial results, the results based on optimal static heating curves, and the adaptive results are compared and critically analysed. Finally, the conclusions are summarized in Section 5.

\section{Simulation data}

\subsection{TRNSYS models of the investigated buildings}

Two different residential buildings were considered in this study. They were constructed using the TRNSYS numerical simulation tool (Klein et al. 2013), which is one of the most powerful house energy simulators (Pedersen 2007). The universality and widespread application of TRNSYS has been demonstrated in many studies (Al-Saadi and Zhai 2015; Crawley et al. 2008; Safa, Fung, and Kumar 2015; Lu et al. 2017) in which it was used to simulate the thermal response of different building structures (e.g. walls, windows, slabs on grade, roofs, and solar walls) in combination with various building services (HVAC, heat pumps, solar systems, etc.).

The two investigated buildings, which were denoted B1 and B2, were designed with two floors and $180 \mathrm{~m}^{2}$ of total living space, external dimensions of $8 \times 11 \mathrm{~m}$, and a double-pitched roof with a N-S orientation. Buildings B1 and B2 were designed as modifications of the reference building (described in Section 2.2) to represent typical Slovenian family houses. The structures of the external and internal opaque walls were assumed to be of heavyweight construction ("ISO 13790: 2008 Energy Performance of Buildings - Calculation of Energy Use for Space Heating and Cooling" 2008). Whereas building B1 represents a new building constructed according to the Regulations on energy efficiency in buildings ("Directive 2010/31/EU of the European Parliament and of the Council of 19 May 2010 on the Energy Performance of Buildings (Recast)" 2010), building B2 represents an older building. Buildings with two zones were constructed in a TRNSYS Multi-zone building model (Type 56b), and the other main components of the TRNSYS models included: Type 9 (the data read model), Type 16 (the solar radiation processor model), Type 69 (the long-wave radiation exchanger model), Type 33 (the psychometrics model), Type 25 (the printer module), Type 581 (the multi-dimensional 
data interpolation model for the heat pump), Type 2 (the ON/OFF Differential Controller), and Type Equa (for different mathematical operation). Simulation was performed at one hour time intervals. The technical and thermal properties of both of the investigated buildings are summarized in Table 1, and the corresponding graph of the TRNSYS model is shown in Figure 1. The TRNSYS model is the same for all the considered buildings and only Type 56b (defining the building characteristics) is modified for each building according to the building plan and envelope construction.

\begin{tabular}{llll}
\hline Description & Unit & Building B1 & Building B2 \\
\hline \hline Living area & {$\left[\mathrm{m}^{2}\right]$} & 180 & 180 \\
$U_{\text {exterior wall }}$ & {$\left[\mathrm{W} / \mathrm{m}^{2} \mathrm{~K}\right]$} & 0.33 & 0.55 \\
$\mathrm{U}_{\text {roof }}$ & {$\left[\mathrm{W} / \mathrm{m}^{2} \mathrm{~K}\right]$} & 0.13 & 0.40 \\
$\mathrm{U}_{\text {floor }}$ & {$\left[\mathrm{W} / \mathrm{m}^{2} \mathrm{~K}\right]$} & 0.16 & 0.46 \\
$\mathrm{U}_{\text {glazing }}$ & {$\left[\mathrm{W} / \mathrm{m}^{2} \mathrm{~K}\right]$} & 1.30 & 2.83 \\
gglazing $_{\text {Shading factor }(\mathrm{Sf})}$ & {$[/]$} & 0.55 & 0.76 \\
& {$[/]$} & 0.75 if Tin $>$ & 0.75 if Tin $>24^{\circ} \mathrm{C}$ \\
Infiltration & & $24^{\circ} \mathrm{C}$ & 0.4 \\
Ventilation & {$[\mathrm{ACH}]$} & 0.2 & 0.5 \\
Internal heat gains & {$[\mathrm{ACH}]$} & 0.5 & 5.0 \\
Specific energy demand & {$\left[\mathrm{W} / \mathrm{m}^{2}\right]$} & 5.0 & 87.5 \\
\hline
\end{tabular}

Table 1: Technical and thermal properties of the two investigated buildings, B1 and B2

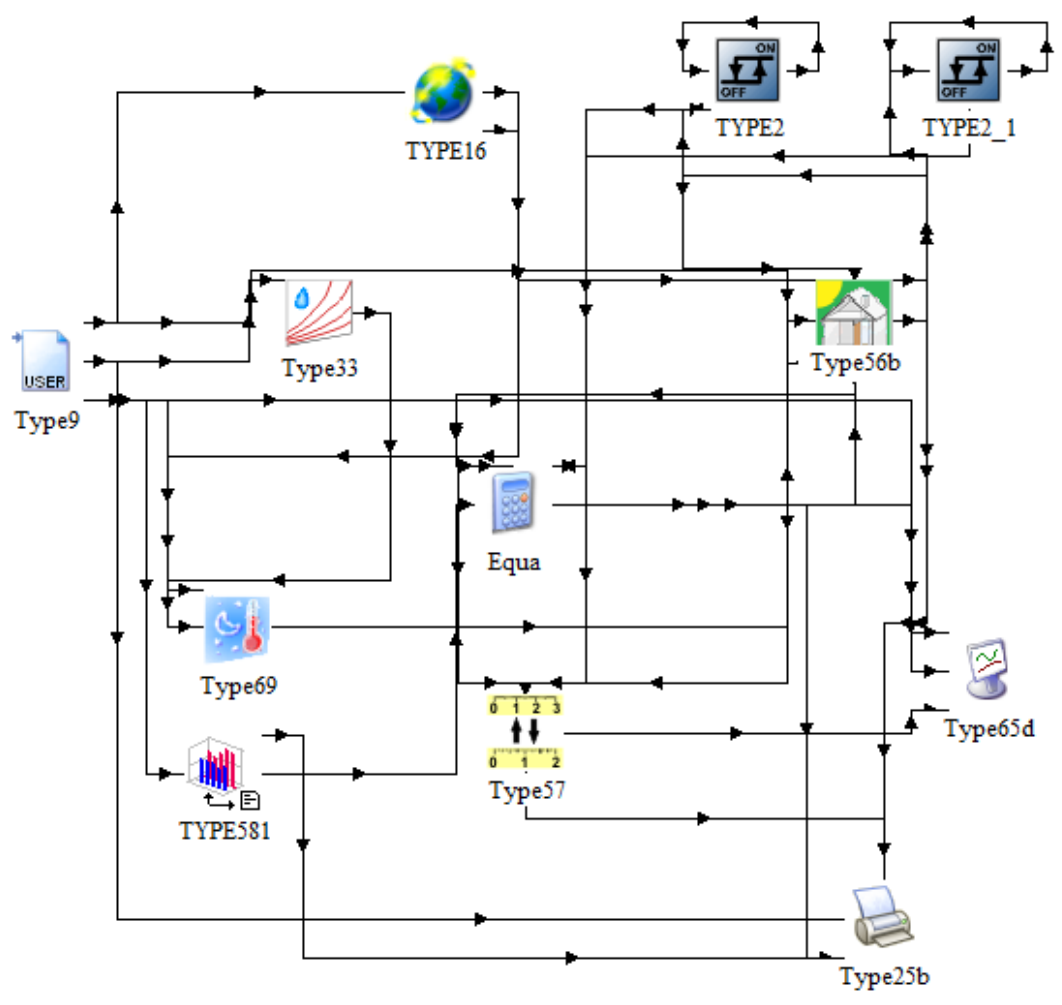

Figure 1: TRNSYS model of the buildings considered in our study

The buildings were designed as being occupied, except during weekdays from 7 AM till 4 PM. During the occupied hours the air exchange rate was $0.5 \mathrm{ACH}$ (air changes per hour), whereas during the unoccupied hours the air exchange rate was reduced to $0.2 \mathrm{ACH}$ and $0.4 \mathrm{ACH}$, which 
corresponds to the airtightness of the buildings. The internal heat gains $Q_{\text {in }}$ (people, home appliances, and lighting) were estimated to amount to $5 \mathrm{~W} / \mathrm{m}^{2}$ of the building floor area, and were taken into account during the occupied hours.

The heating system in both buildings was assumed to consist of a heat pump (air-water) and a floor heating system. Heat pumps achieve higher efficiencies (expressed as COP - coefficient of performance) when the temperature of the heat transfer fluid $T_{\text {heat }}$ is lower. For this reason, we took into account a floor heating system consisting of a pipe system with two loops, i.e. a primary and a secondary loop. The primary loop was connected to the heat pump and the pipe distributor in each zone, where we assumed a pipe with five loops (the secondary loop) which is located in the concrete layer. In the primary loop we assumed that the temperature regulation was carried out by the heat pump itself, so that we did not take into account any additional thermostatic valves or a heat buffer storage. In the secondary loop, the on/off regulation implemented by an ON/OFF differential controller model (Type 2b) was taken into account.

\subsection{Validation of the TRNSYS model}

The numerical model of the building and the heating system were verified by comparing the results for the simulated and the measured thermal response of the reference building and the floor heating system. The reference building is a low energy building similar to B1, located near Celje, Slovenia, and is shown in Figure 2. The reference building was the basis for the development of TRNSYS simulations B1 and B2.

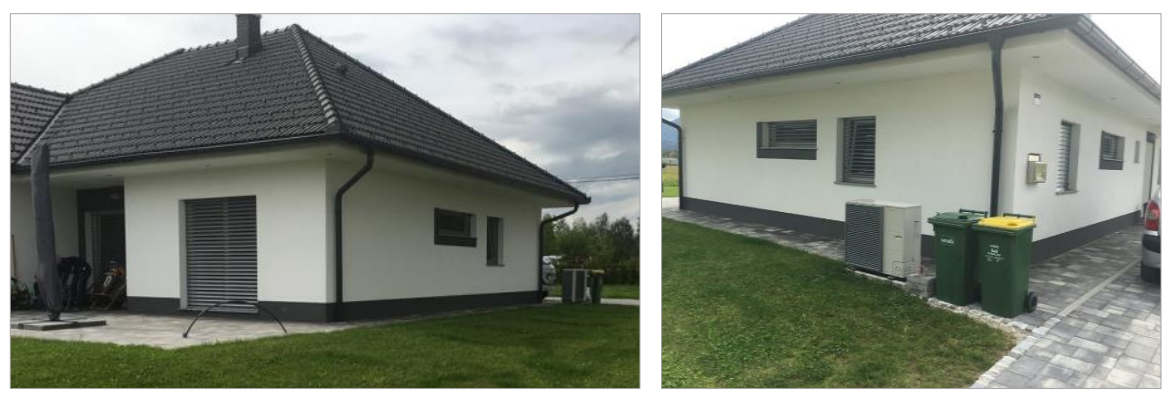

Figure 2: Photo of a reference building near Celje, Slovenia

Temperature and solar radiation measurements were performed over a two-week period in February 2017. The indoor temperature was measured near the entrance to a living room, and the outdoor temperature was measured near the outdoor heat pump unit (shown in Figure 2, right). The temperature of the heating system ( $\left.T_{\text {heat }}\right)$ was measured at the output of the condenser of the heat pump. The data about solar radiation were obtained from the nearest weather recording station, which was approximately $13 \mathrm{~km}$ distant from the location of the building. A bias of $\Delta T_{\text {in }}=0.35^{\circ} \mathrm{C}$ was removed from the modelled indoor temperatures as a post-processing step. Figure 3 shows the relationship between the measured temperature and the numerically defined heating temperature $T_{\text {heat }}$ (upper plot) and the indoor air temperature $T_{\text {in }}$ (lower plot). The scatter plots on the right hand side show the correlation between the measured and modelled values, which can be expressed by means of the correlation coefficient $\mathrm{R}=0.996$ in the case of $T_{\text {heat, }}$, and the correlation coefficient $\mathrm{R}=0.937$ in the case of $T_{\mathrm{in}}$. It can be concluded from the results of the comparison that the numerical model was successfully verified, and therefore suitable for the simulation study presented in this paper. 

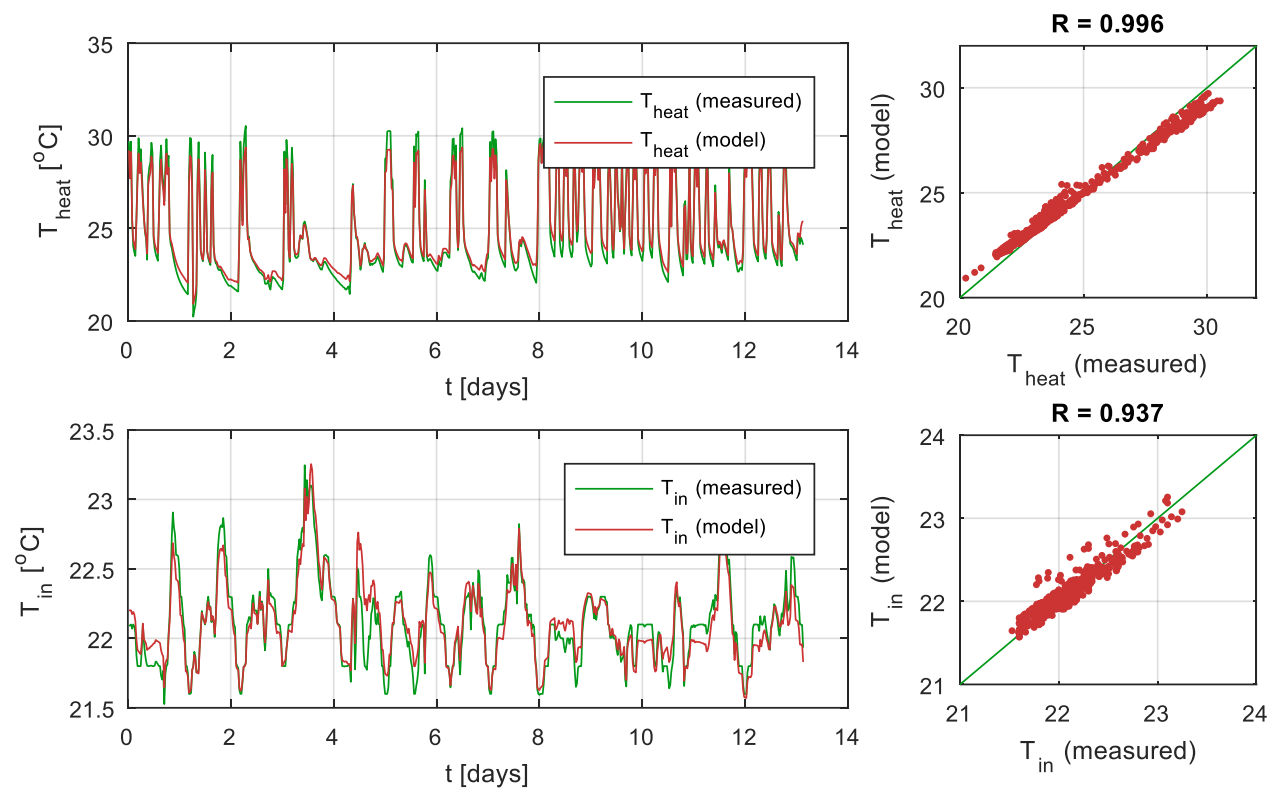

Figure 3: Experimental verification of the numerical model for the reference building: heating temperature $T_{\text {heat }}$ (upper plot), and indoor air temperature $T_{\text {in }}$ (lower plot)

\subsection{Weather data}

The simulations performed in this paper were based on weather data which were recorded in Ljubljana, Slovenia, during a typical winter season (ARSO 2017). These data include hourly measurements of the outdoor temperature $T_{\text {out }}$ and the solar radiation $S R$ for a period of six months. Figure 4 shows a boxplot with the hourly distribution of outdoor temperatures (left), and a histogram showing the overall outdoor temperature distribution (right).
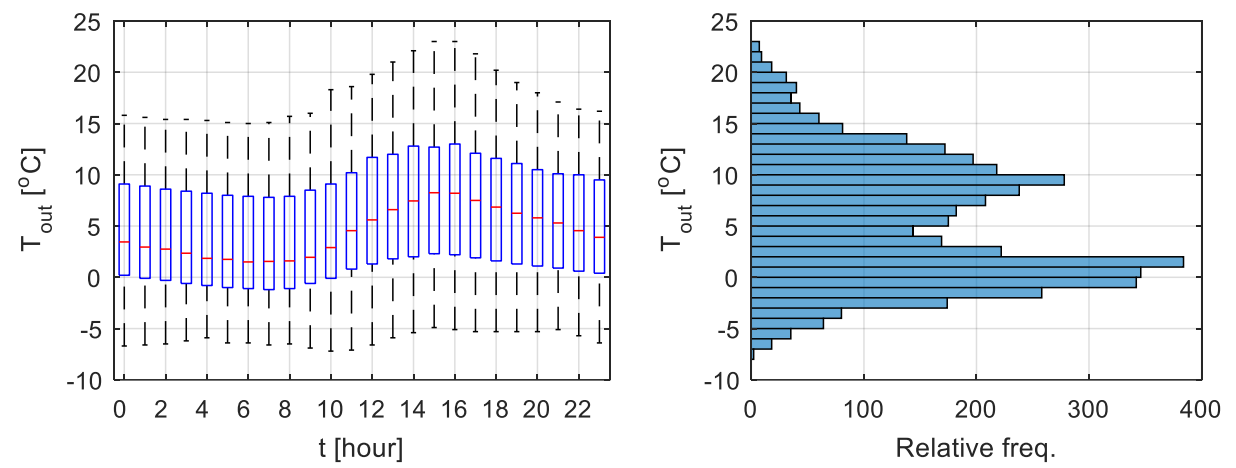

Figure 4: Weather data recorded at Ljubljana, Slovenia, showing the distribution of outdoor temperature $T_{\text {out }}$ for the six months of a winter period

\section{Methods}

In the paper a simple two-point parametrization of the heating curve is proposed, and then static and various adaptive solutions are discussed with regard to the tracking of the desired indoor temperature

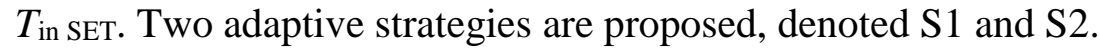

\subsection{Parametrization of the heating curve}

The so called heating curve defines the weather controlled heating regime, where the temperature of the indoor heating fluid - water supply temperature $T_{\text {heat }}$ is proportional to the weather related parameters. The heating curve is designed to increase the temperature of the heating fluid with 
decreasing outdoor temperature. In this paper, the heating curve for a weather-controlled heat pump based floor heating is described. Optimization of the weather controlled heating curve in this case too guarantees optimal heating with continuous heat pump operation, which also implies operation with the highest COP (coefficient of performance). The optimal heating curve therefore guarantees good thermal comfort and also reduces operational costs. A typical example of a heating curve, provided by a heat pump manufacturer (Kronoterm, 2017), defines a linear heating curve and proposes initial settings for different building types. Obviously, the suggested settings are rarely optimal for specific buildings and end users have to manually experiment and try to reach optimal settings.

In our study, the most widely applied case is taken into account, where the heating temperature $T_{\text {heat }}$ is linearly related to the outdoor temperature $T_{\text {out }}$, as follows:

$$
T_{\text {heat }}(t)=p_{0}+p_{1} T_{\text {out }}(t)
$$

where $p_{0}$ and $p_{1}$ denote parameters of the linear function, and $t$ denotes time - in this case referring to the instantaneous relationship between the outdoor and indoor temperatures. A linear heating curve is usually sufficient because a heating demand of a building is basically linearly proportional to the outdoor temperature, and only rarely are nonlinear adjustments necessary.

In order to prepare the parametrization for application in the adaptive strategies, the linear relation is further expressed by two reference points, defined by the pairs $T_{\text {heat REF }}\left(T_{\text {out REF }}\right)$ as shown in Figure 5, and expressed as follows:

Reference point 1: $T_{\text {heat REF1 }}\left(T_{\text {out REF1 }}\right)$

Reference point 2: $T_{\text {heat REF2 }}\left(T_{\text {out REF2 }}\right)$

The definition of the reference outdoor temperatures $T_{\text {out REF1 }}$ and $T_{\text {out REF2 }}$ is arbitrary and is not critical. The intention of such a definition is simply that they stretch meaningfully across the range of expected outdoor temperatures. In our case study, the outdoor temperatures $T_{\text {out REF } 1}=0{ }^{\circ} \mathrm{C}$ and $T_{\text {out REF } 2}=20^{\circ} \mathrm{C}$ were selected (as shown in Figure 5). The corresponding heating reference temperatures $T_{\text {heat REF1 }}$ and $T_{\text {heat REF2 }}$ represent the linear parametrization and therefore have a critical influence on the heating system. For this reason the two heating reference temperatures $\left(T_{\text {heat REF1 }}\right.$, $T_{\text {heat REF2 }}$ ) are considered as free parameters, and subject to variation and adaptation in order to achieve an optimal heating solution.

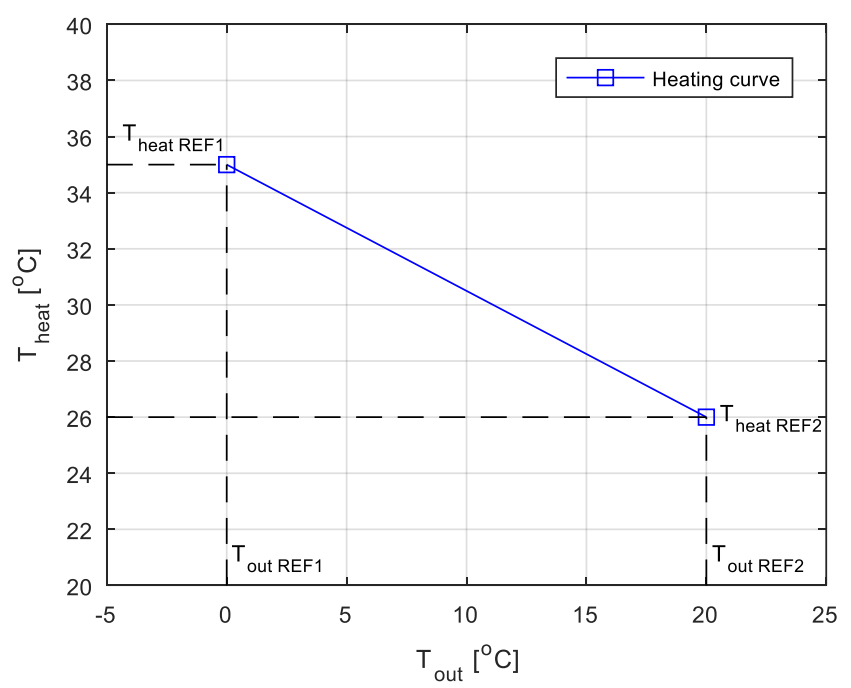

Figure 5: Parametrization of the heating curve by two reference points $\left(T_{\text {out REF1 }}, T_{\text {heat REF1 }}\right)$ and $\left(T_{\text {out REF2 }}, T_{\text {heat REF2 }}\right)$ 


\subsection{Problem formulation}

The goal of this method is to maintain the desired indoor temperature $T_{\text {in Set }}$ in the building by heating the building according to the defined heating curve. In our case study, the desired indoor temperature was defined as $T_{\text {in Set }}=25^{\circ} \mathrm{C}$, which approximately corresponds to PMV (i.e. predicted mean vote) values (Fanger 1970) close to zero for simulated buildings. The optimization goal is expressed here as a Root Mean Square Error (RMSE) between the indoor temperature $T_{\text {in }}$ and the desired indoor temperature $T_{\text {in Set, }}$ i.e.

$$
\operatorname{RMSE}=\sqrt{\frac{\sum_{t=1}^{N}\left(T_{\text {in }}(t)-T_{\text {in Set }}(t)\right)^{2}}{N}}
$$

where $t$ denotes the time in hourly intervals, and $N$ is the length of the observation period. The aim is to minimize the RMSE measure by appropriately adjusting the two heating reference temperatures ( $T_{\text {heat REF1 }}, T_{\text {heat REF2 }}$ ). The only constraint considered in this study is that a heating temperature $T_{\text {heat }}$ above the desired indoor temperature $T_{\text {in Set }}$ is maintained, as follows:

$$
\forall t: T_{\text {heat }}(t) \geq T_{\text {in Set }}(t)
$$

This constraint guarantees the operation of the heating regime at all times, with no cooling periods, and even this constraint can be eliminated in the case of heating systems that allow combined heating/cooling regimes.

\subsection{Optimization of static heating curves}

The optimization of the RMSE criterion (Eq. 2) can be either static, or dynamic (adaptive). In the static optimization, we are searching for the optimal fixed values of the two heating reference temperatures ( $T_{\text {heat REF1 }}, T_{\text {heat REF2 }}$ ), which will remain constant throughout the whole heating season, and yield a minimum RMSE value. Although many different methods are available for the optimization of reference temperatures with respect to the RMSE criterion, in our research, a heuristic global search algorithm (Ugray et al. 2007) was applied as an optimization method due to its simplicity, efficiency, and robustness of operation. The algorithm, called OptQuest/NLP or OQNLP, is a heuristic designed to find global optima for nonlinear problems with many constraints and variables, where all problem functions are differentiable with respect to the continuous variables. It uses OptQuest, a commercial implementation of scatter search (Laguna and Marti 2002), to provide starting points for any gradient-based local solver for nonlinear programming (NLP) problems. This solver seeks a local solution from a subset of these points, holding discrete variables fixed. The procedure combines the superior accuracy and feasibility-seeking behaviour of gradient-based local NLP solvers with the global optimization abilities of OptQuest. The algorithm stops when it runs out of start points (and corresponding gradient based local solvers). Details of the algorithm are described in (Ugray et al. 2007). The optimization framework was implemented in Matlab, so that the complete optimization approach therefore combines Matlab based numerical optimization, and TRNSYS based simulation models of the buildings.

\subsection{Adaptive optimization of the heating curves}

In adaptive approach to the optimization of the RMSE criterion, the two heating reference temperatures ( $T_{\text {heat REF1 }}, T_{\text {heat REF2 }}$ ) are dynamically adjusted during the operation, according to the defined adaptation mechanisms. The generic problem of adaptive optimization is the need for error 
gradients according to which the appropriate adaptation can take place. If a model of the buildingheating system is not available (which is the case under consideration), the error gradients and their time delays cannot be calculated directly, so that iterative stochastic learning methods must be applied. In this paper, the two adaptive strategies that are proposed and investigated, denoted S1 and $\mathrm{S} 2$, are described in the following subsections. Both of these strategies rely on the instantaneous error $E(\mathrm{t})$ between the indoor temperature $T_{\text {in }}$ and the desired indoor temperature $T_{\text {in Set: }}$ :

$$
E(t)=T_{\text {in }}(t)-T_{\text {in Set }}(t)
$$

The adaptation of each reference point ( $\left.T_{\text {heat REF1 }}, T_{\text {heat REF2 }}\right)$ is performed according to the adaptation rule:

$$
T_{\text {heat REFi }}(t+1)=T_{\text {heat REFi }}(t)-E(t) K w_{\mathrm{i}}\left(T_{\text {out }}\right) ; i=1,2 ;
$$

which corrects the value of each reference point $T_{\text {heat REFi, }} i=1,2$; according to the error $E(t)$, the adaptation constant $K$, and a weighting function $w_{\mathrm{i}}$. The instantaneous error $E(t)$ does not provide an accurate gradient feedback due to the complexity of the building-heating system, but it is easily available, and this study investigates the possibilities of exploiting this information for automatic iterative adaptation of the heating curve.

The adaptation constant $K$ is a free parameter and determines the speed of adaptation. In our study, many different values were investigated, i.e. $K=\{0.01,0.02,0.05,0.1,0.2,0.5,1\}$, and the results presented in Section 4 show the influence of this parameter.

The weighting function $w_{\text {i }}$ proposed in this paper is a distribution mechanism with respect to the strategy $\mathrm{S}$ which is used to distribute the adaptation across the two reference points, where $w_{1}$

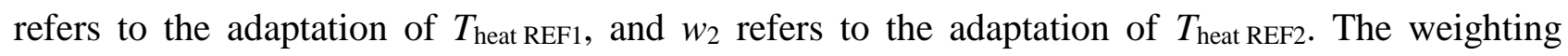
function $w_{\mathrm{i}}$ is a function of the outdoor temperature $T_{\text {out }}$. This function can be defined in many different ways, however in this paper two basic strategies S1 and S2 are proposed, and are described in the next subsections. These two strategies can be considered as two characteristic examples, one a piecewise linear continuous function, and the other a hard-limiting function. Many more possibilities can be designed in between, such as sigmoidal continuous functions with various degrees of steepness. Although the choice of the weighting function seems an important part of the designing of the adaptation strategy, the results presented in Section 4 reveal robustness with respect to the design of the weighting function.

\subsubsection{Adaptive strategy S1}

This strategy defines the piecewise linear weighting functions $w_{1}$ and $w_{2}$ as follows, expressed in pseudocode:

$$
\begin{array}{ll}
\text { if } T_{\text {out }}<T_{\text {out REF1 }} & : w_{1}=1 \text { and } w_{2}=0 \\
\text { if } T_{\text {out }}>T_{\text {out REF2 } 2} & w_{1}=0 \text { and } w_{2}=1 \\
\text { else } & : w_{1}=\left(T_{\text {out }}-T_{\text {out REF1 } 1}\right) /\left(T_{\text {out REF2 }}-T_{\text {out REF1 }}\right) \text { and } w_{2}=1-w_{1}
\end{array}
$$

The sum of both weighting functions is always equal to one: $w_{1}+w_{2}=1$. Figure 6 (left) illustrates the weighting functions $w_{1}$ and $w_{2}$ for the adaptive strategy S1 across the complete range of considered outdoor temperatures. 


\subsubsection{Adaptive strategy $S 2$}

The second adaptation strategy represents an even more simplified case and defines the hard-limiting weighting functions $w_{1}$ and $w_{2}$ with respect to the mean of both reference outdoor temperatures $T_{\text {out REFmean }}=\left(T_{\text {out REF2 }}-T_{\text {out REF1 }}\right) / 2$, as follows:

$$
\begin{array}{ll}
\text { if } T_{\text {out }}<T_{\text {out REFmean }} & : w_{1}=1 \text { and } w_{2}=0 \\
\text { if } T_{\text {out }} \geq T_{\text {out REFmean }} & : w_{1}=0 \text { and } w_{2}=1
\end{array}
$$

In this case, too, the sum of both weighting functions always amounts to one. Figure 6 (right) illustrates the weighting functions $w_{1}$ and $w_{2}$ for the adaptive strategy S2 across the complete range of considered outdoor temperatures.
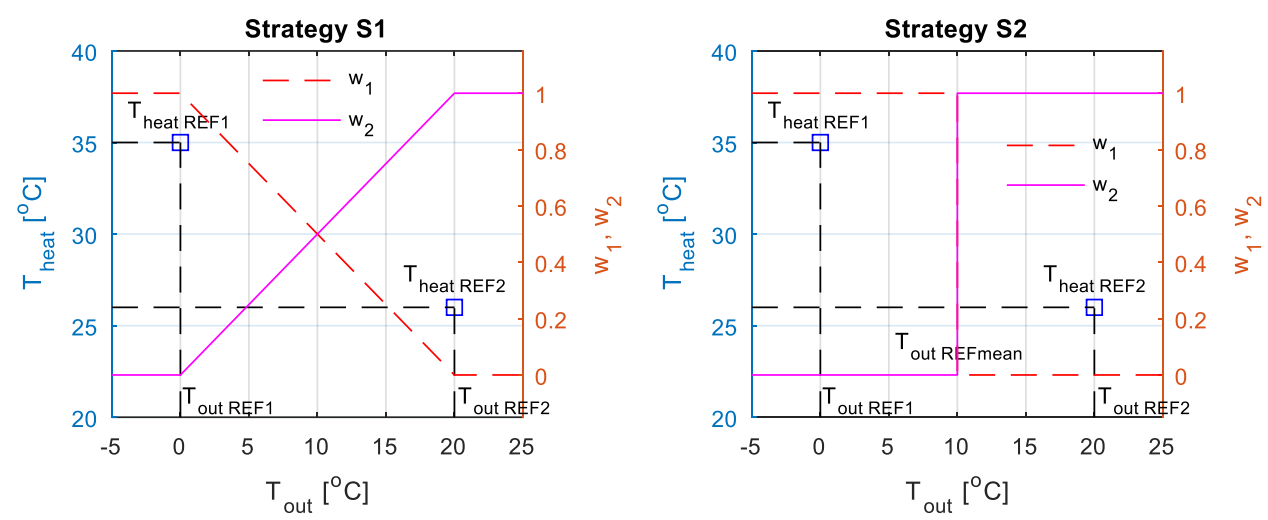

Figure 6: Illustration of the weighting functions $w_{1}$ and $w_{2}$ for both adaptation strategies, S1 and S2

\subsection{Simulation workflow}

Based on the described parametrization of the heating curve, the following experiments were performed for both buildings B1 and B2:

1. Initial simulation based on the heuristically chosen initial heating curve (which corresponds to a possible initial setup in a real building).

2. Calculation of optimal static heating curves. These curves represent the optimal static results and can be considered as benchmarks for comparison of the adaptive approaches.

3. Calculation of adaptive heating curves:

a. according to strategies S1 and S2, and

b. with respect to different adaptation constants $K=\{0.01,0.02,0.05,0.1,0.2,0.5$, $1\}$.

The optimization and adaptation methods were implemented in Matlab and connected to a TRNSYS simulation, in which calculations of the buildings' response in hourly intervals were performed. Finally, the results were summarized and analysed in a comparative manner, as presented in the next section.

\section{Results}

\subsection{Initial results}

In order to assess the situation that can occur in a real building with arbitrary initial settings of the heating curve, the initial heating curve was defined for both buildings as follows:

$$
T_{\text {heat REF1 }}=35.0{ }^{\circ} \mathrm{C} \text {, and } T_{\text {heat REF2 }}=26.0{ }^{\circ} \mathrm{C} \text {. }
$$


The selection of reference heating temperatures $35^{\circ} \mathrm{C}$ and $26^{\circ} \mathrm{C}$ was chosen to be far from optimal values for both buildings in order to demonstrate the performance of the proposed adaptive strategies. This selection also represents a possible initial setting of a heat pump installed in a building. Figure 7 shows the initial simulation results for both buildings. The first building B1 suffers from overheating, and the second building B2 is under-heated. The RMSE values amount to RMSEB1 = $1.916{ }^{\circ} \mathrm{C}$, and $\mathrm{RMSE}_{\mathrm{B} 2}=1.711^{\circ} \mathrm{C}$. It is clear that buildings $\mathrm{B} 1$ and $\mathrm{B} 2$ require different heating curves due to their different construction, building envelopes, windows, etc.

In Figure 7 (and the subsequent figures), the reference heating temperatures $T_{\text {heat REF1 }}$ and $T_{\text {heat REF2 }}$ are indicated by bold blue and cyan lines, whereas the actual temperature of the heating fluid $T_{\text {heat }}$ (calculated according to the heating curve defined by $T_{\text {heat REF1 }}$ and $T_{\text {heat REF2 }}$ ) is indicated by a green line, and the desired and actual indoor temperatures $T_{\text {in Set }}$ and $T_{\text {in }}$ are indicated by a dashed red line and a red line. The optimal static values for both of the reference heating temperatures ( $T_{\text {heat REF1 }}$

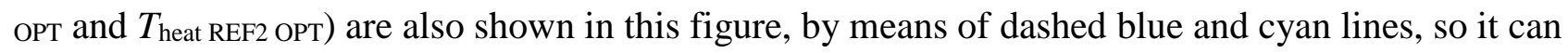
be seen that in this initial case these reference temperatures are far from optimal.
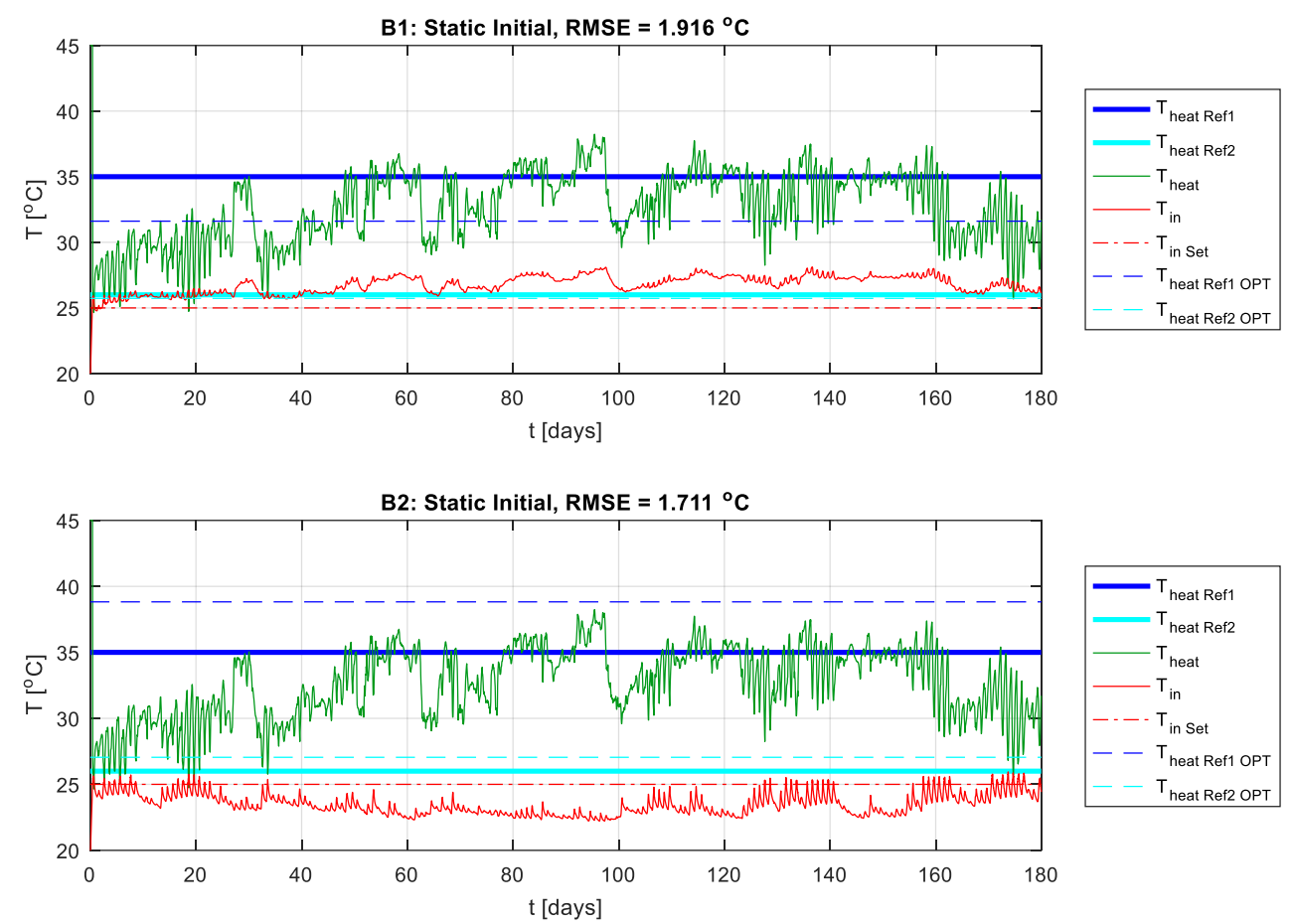

Figure 7: Initial (non-optimal) static heating curves for buildings B1 and B2

\subsection{Optimal static results}

The second result corresponds to the off-line optimization of the static reference heating temperatures, where the following values were obtained for building $\mathrm{B} 1$ :

$T_{\text {heat REF1 OPT }}=31.6{ }^{\circ} \mathrm{C}$, and $T_{\text {heat REF2 OPT }}=25.7^{\circ} \mathrm{C}$,

and for building B2:

$T_{\text {heat REF1 OPT }}=38.8^{\circ} \mathrm{C}$, and $T_{\text {heat REF2 OPT }}=27.1^{\circ} \mathrm{C}$,

The corresponding RMSE values are $\mathrm{RMSE}_{\mathrm{B} 1}=0.286{ }^{\circ} \mathrm{C}$, and $\mathrm{RMSE}_{\mathrm{B} 2}=0.338{ }^{\circ} \mathrm{C}$, which represent the best possible result within the context of the static heating curves. The optimal static results are shown in Figure 8. 

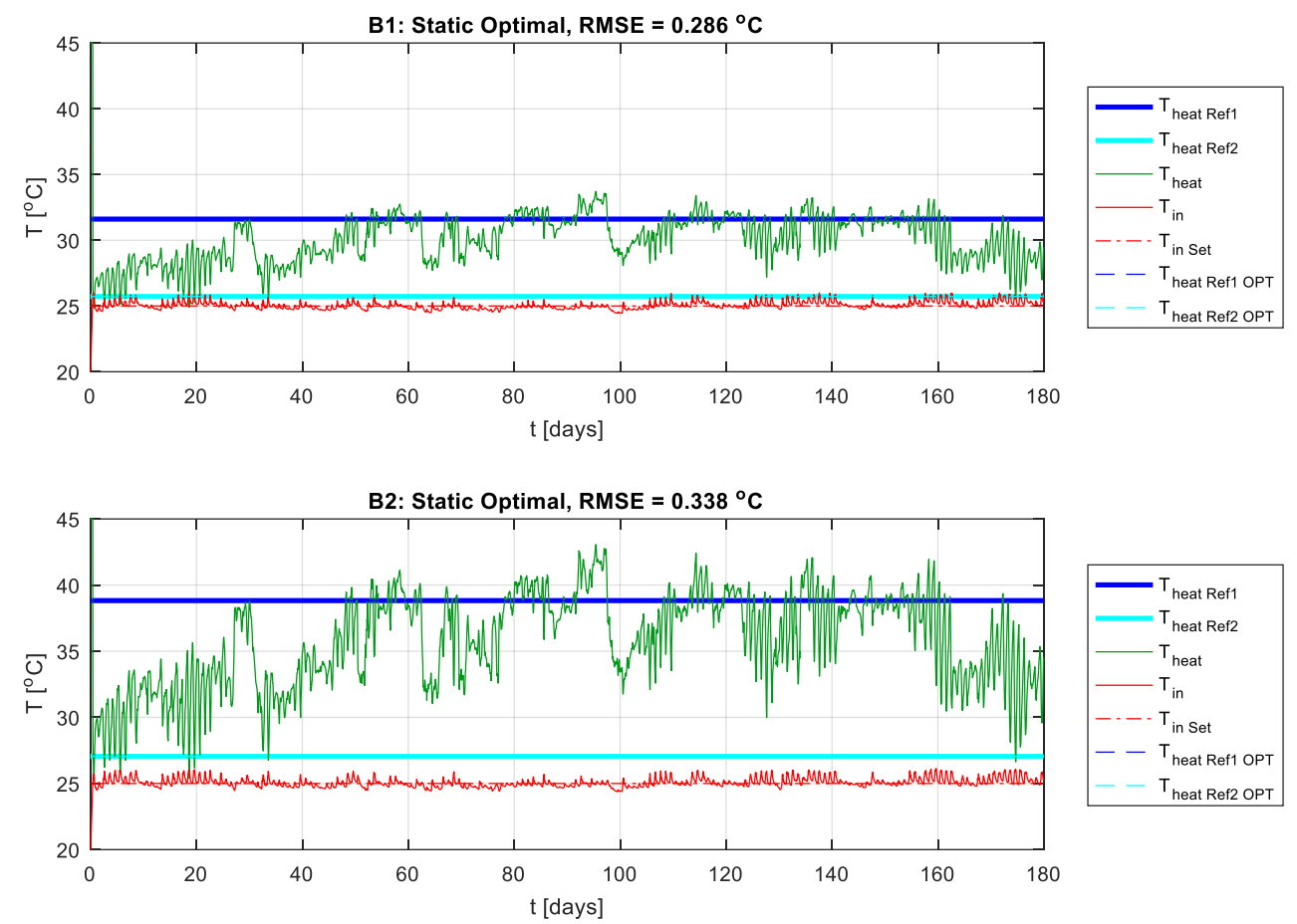

Figure 8: Optimal static heating curves for buildings B1 and B2

\subsection{Adaptive results}

In the next step, calculation of the adaptive results was performed by examining both proposed strategies $\mathrm{S} 1$ and $\mathrm{S} 2$, and investigating the range of adaptation constants $K=\{0.01,0.02,0.05,0.1$, $0.2,0.5,1\}$. Several selected results are shown in Figures 9 and 10, and the results of all the performed experiments are summarized and discussed in the next subsection.

The results for both proposed strategies are quite similar, so only a few results for strategy S1 are shown, and for two very different adaptation constants. Figure 9 presents the adaptive results for both of the investigated buildings, and for an adaptation constant $K=0.05$, which defines slower and less fluctuating adaptation. It can be seen from this figure that both of the reference heating temperatures $T_{\text {heat REF1 }}$ and $T_{\text {heat REF2 }}$ converge toward optimal static settings, and the characteristic adaptation time (from the initial settings) is approximately one month. The second reference heating temperature $T_{\text {heat REF2 }}$ exhibits a slight seasonal fluctuation, and after converging toward the optimal static value, it starts to decrease toward lower values with increasing seasonal outdoor temperatures. 

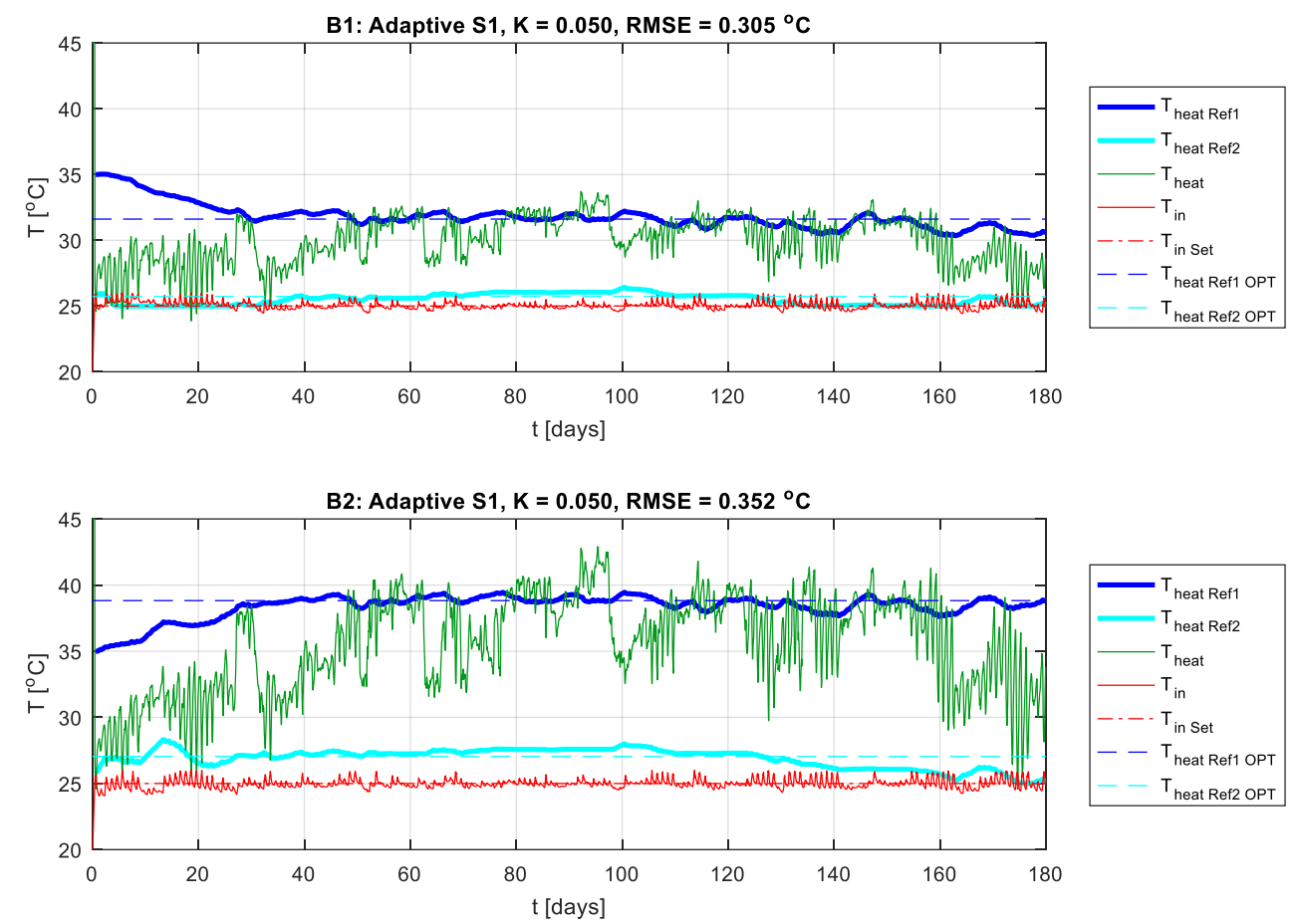

Figure 9: Adaptive heating curves for buildings B1 and B2; adaptation constant $K=0.05$, strategy S1

In Figure 10 the results are presented for a $10 \times$ higher value of the adaptation constant, i.e. $K$ $=0.5$, which results in a fast and very dynamic adaptation of the reference heating temperatures. Again, both of the reference heating temperatures $T_{\text {heat REF1 }}$ and $T_{\text {heat REF2 }}$ converge towards the optimal static settings, and keep fluctuating there, and the characteristic adaptation time is approximately only one week. The second reference heating temperature $T_{\text {heat REF2 }}$ tends to stick toward the lower bound,

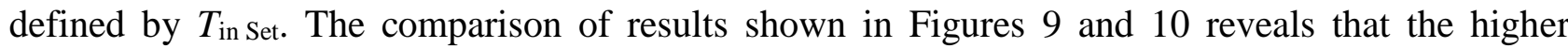
adaptation constant $(K=0.5)$ yields a better performance. Comparison of all the obtained results is presented and discussed in the next subsection.
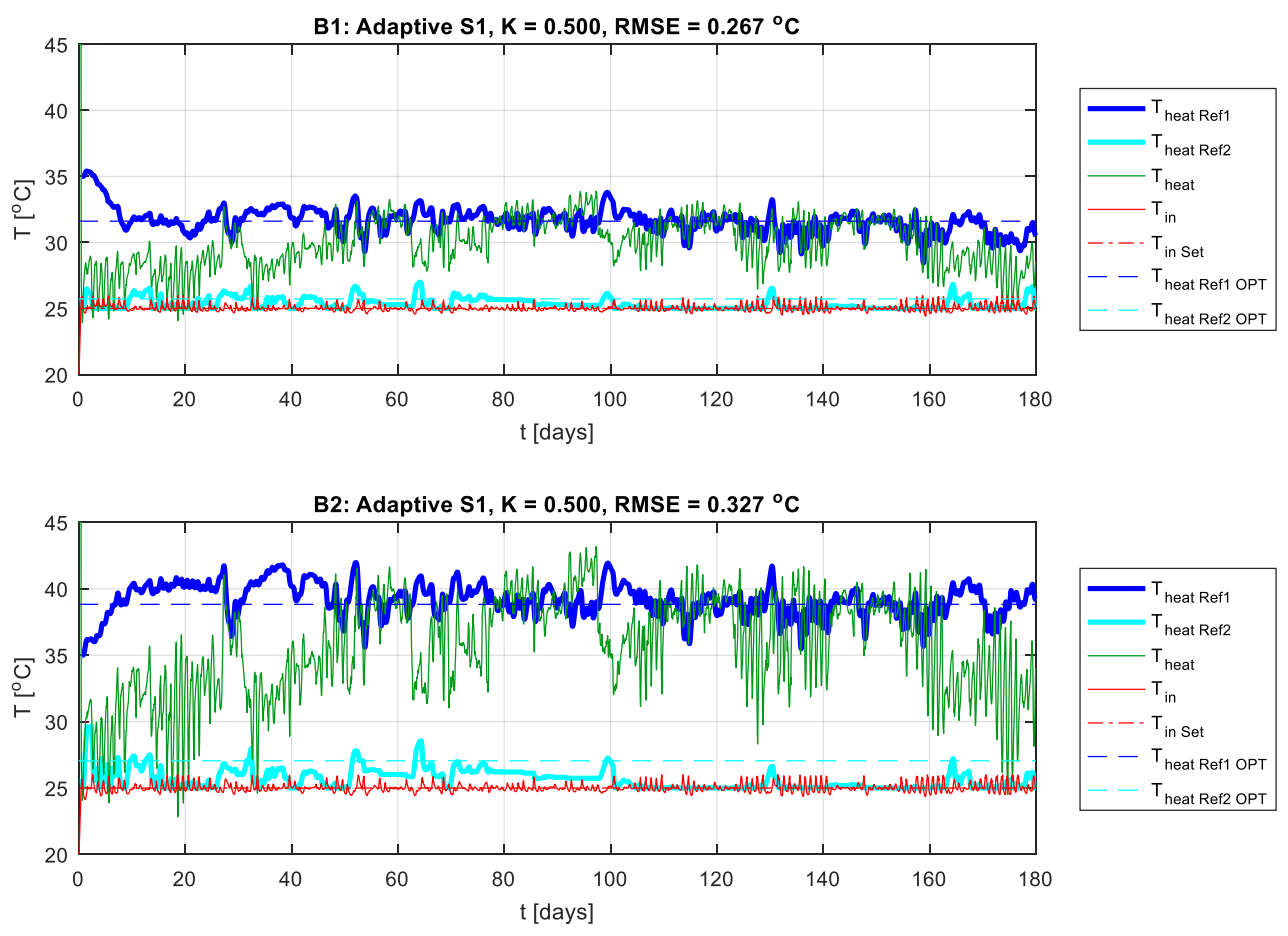

Figure 10: Adaptive heating curves for buildings B1 and B2; adaptation constant $K=0.5$, strategy S1 


\subsection{Comparative analysis of the results}

The simulation results are summarized in Figures 11 and 12. Different adaptation constants result in different characteristic adaptation times, so the results of the tracking of the desired indoor temperature are compared and evaluated with initial transient period removed from the evaluation of RMSE measures.

In Figure 11 the first three days were removed from the results, whereas the remaining data were used in the calculation of the RMSE values. In Figure 12 the first 31 days were removed from the calculation of RMSE values. Thus Figure 11 presents results that partially include the transient period, and Figure 12 presents the stable long-term adaptation. Both figures separately show the results for building B1 (left) and building B2 (right), and all the results are compared to the reference values, defined by the optimal static heating curves (indicated in red). The different applied strategies are denoted in light blue (strategy S1) and blue (strategy S2).
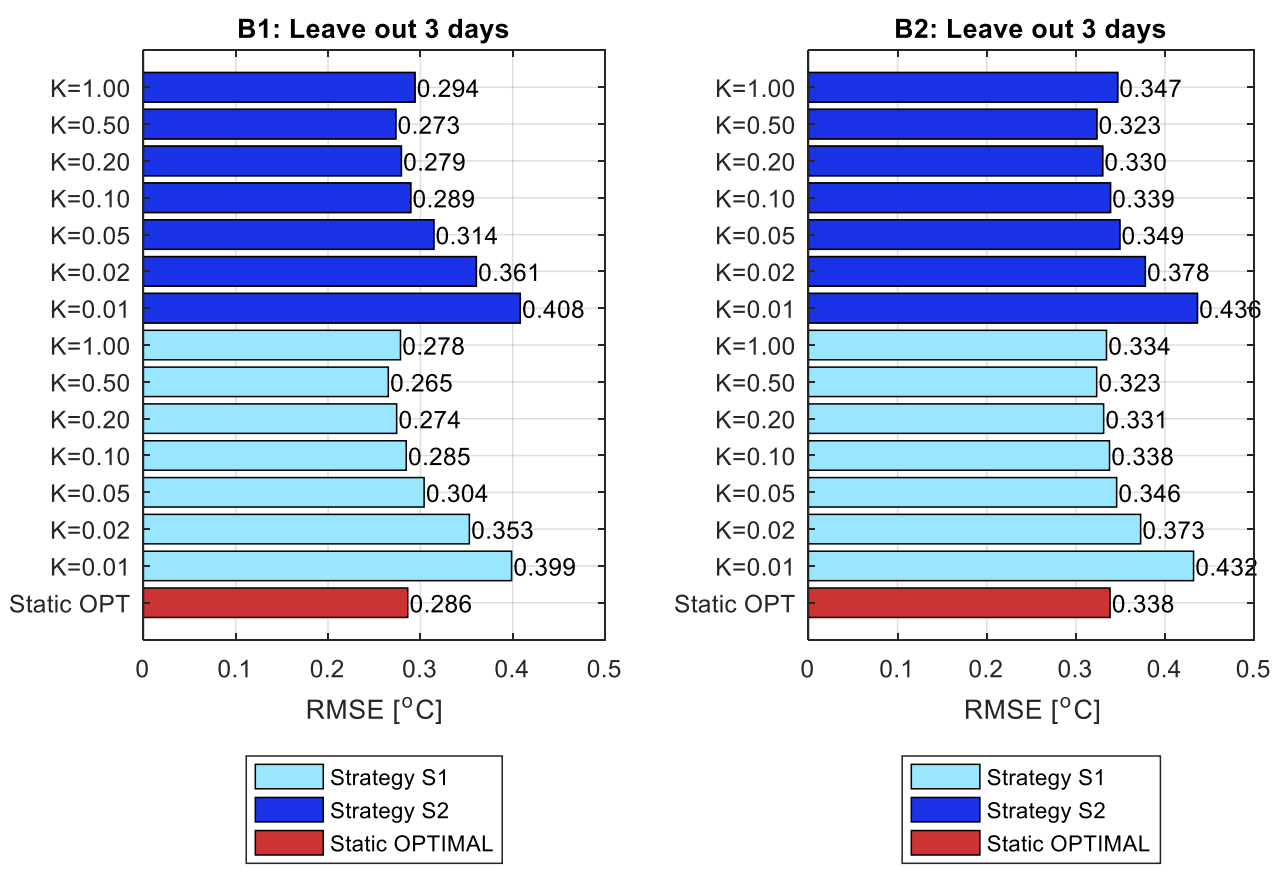

Figure 11: Results for different adaptation constants $K$, the two strategies $\mathrm{S} 1$ and $\mathrm{S} 2$, and buildings $\mathrm{B} 1$ and $\mathrm{B} 2$, after removal of the first 3 days from the RMSE calculation. 

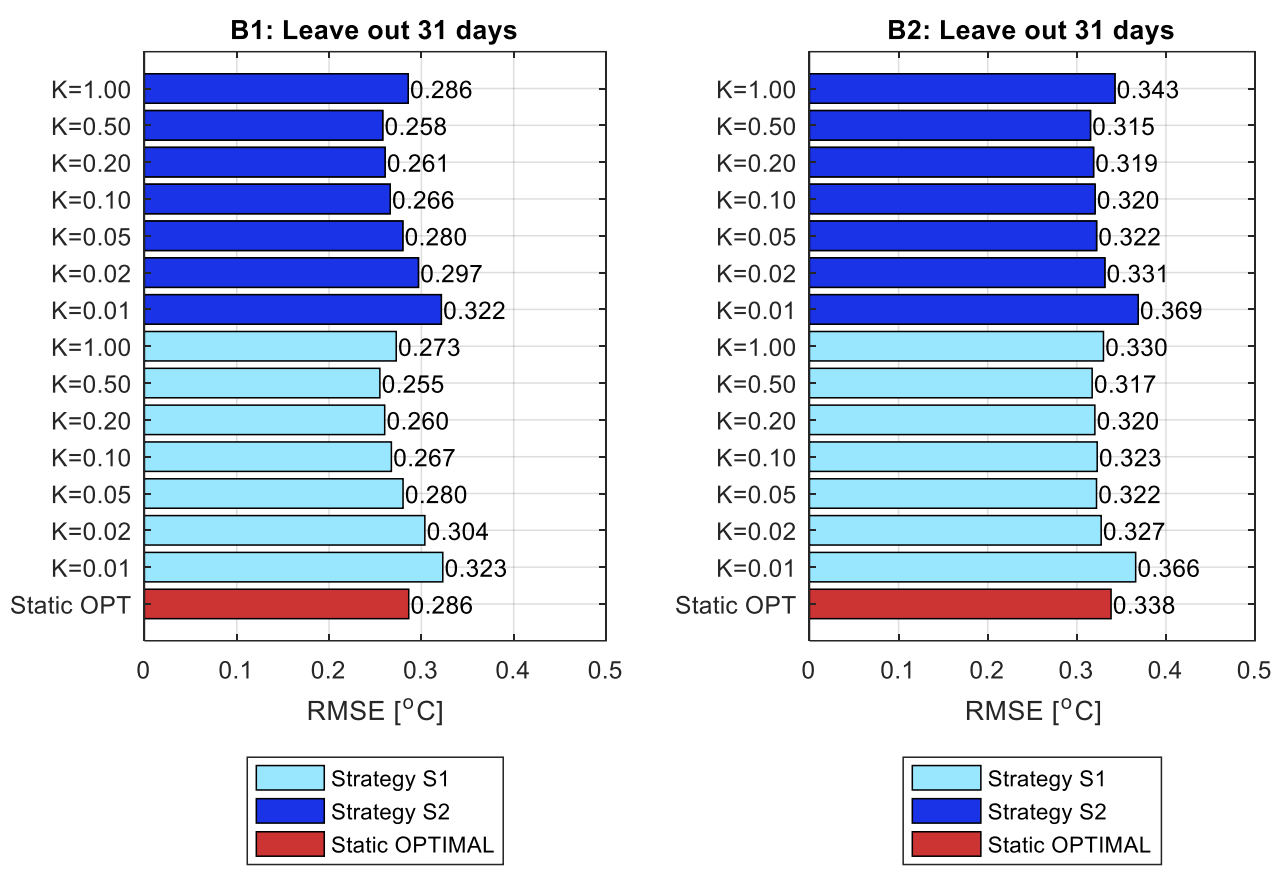

Figure 12: Results for different adaptation constants $K$, the two strategies $\mathrm{S} 1$ and $\mathrm{S} 2$, and buildings B1 and B2, after removal of the first 31 days from the RMSE calculation.

\subsubsection{Discussion of the results with 3 days removed}

In this case (Figure 11), the best adaptation constant is $K=0.5$ for both buildings B1 and B2, and for both strategies S1 and S2. Strategy S1 with the piecewise linear weighting functions $w_{1}$ and $w_{2}$ performs slightly better than strategy $\mathrm{S} 2$. The overall best results for both buildings (strategy $\mathrm{S} 1, K=$ 0.5 ) yield $\mathrm{RMSE}_{\mathrm{B} 1}=0.265{ }^{\circ} \mathrm{C}$, and $\mathrm{RMSE}_{\mathrm{B} 2}=0.323{ }^{\circ} \mathrm{C}$ which is better than the results which are obtained by applying the optimal static heating curves. In case of strategy S1, the range of adaptation constants that result in better performance than the optimal static heating curve is $K=\{0.1,0.2,0.5$, $1\}$, and in the case of strategy $\mathrm{S} 2, K=\{0.2,0.5\}$.

\subsubsection{Discussion of the results with 31 days removed}

This case (Figure 12) corresponds to stable long-term adaptation. Here, too, the best adaptation constant is $K=0.5$ for both buildings B1 and B2, and for both strategies S1 and S2. In general, strategy S1 performs slightly better than strategy S2. The overall best results for both buildings yield $\mathrm{RMSE}_{\mathrm{B} 1}=0.255^{\circ} \mathrm{C}$, and $\mathrm{RMSE}_{\mathrm{B} 2}=0.315^{\circ} \mathrm{C}$, which is again better than the results which are obtained by applying the optimal static heating curves. The range of adaptation constants which yield better performance than the optimal static heating curve is, in this case, even wider.

The results confirm that the proposed adaptive approach is suitable for the adaptation of heating curves in buildings. Compared to the optimal static heating, superior tracking of the desired indoor temperature can be achieved by using the proposed simple adaptation mechanism and appropriate adaptation constants.

Some examples of heating curves for both buildings B1 (left) and B2 (right) are presented graphically in Figure 13. The straight blue and red lines indicate the initial and optimal static heating curves. Whereas the initial static heating curve is the same for both buildings, and represents the starting point for adaptation, the optimal heating curves are different due to the different structural properties of buildings B1 and B2. The curved green lines represent the optimal adaptive heating 
(strategy S1, adaptation constant $K=0.5$ ), which in both buildings moves toward and then fluctuates around the optimal static heating curves.
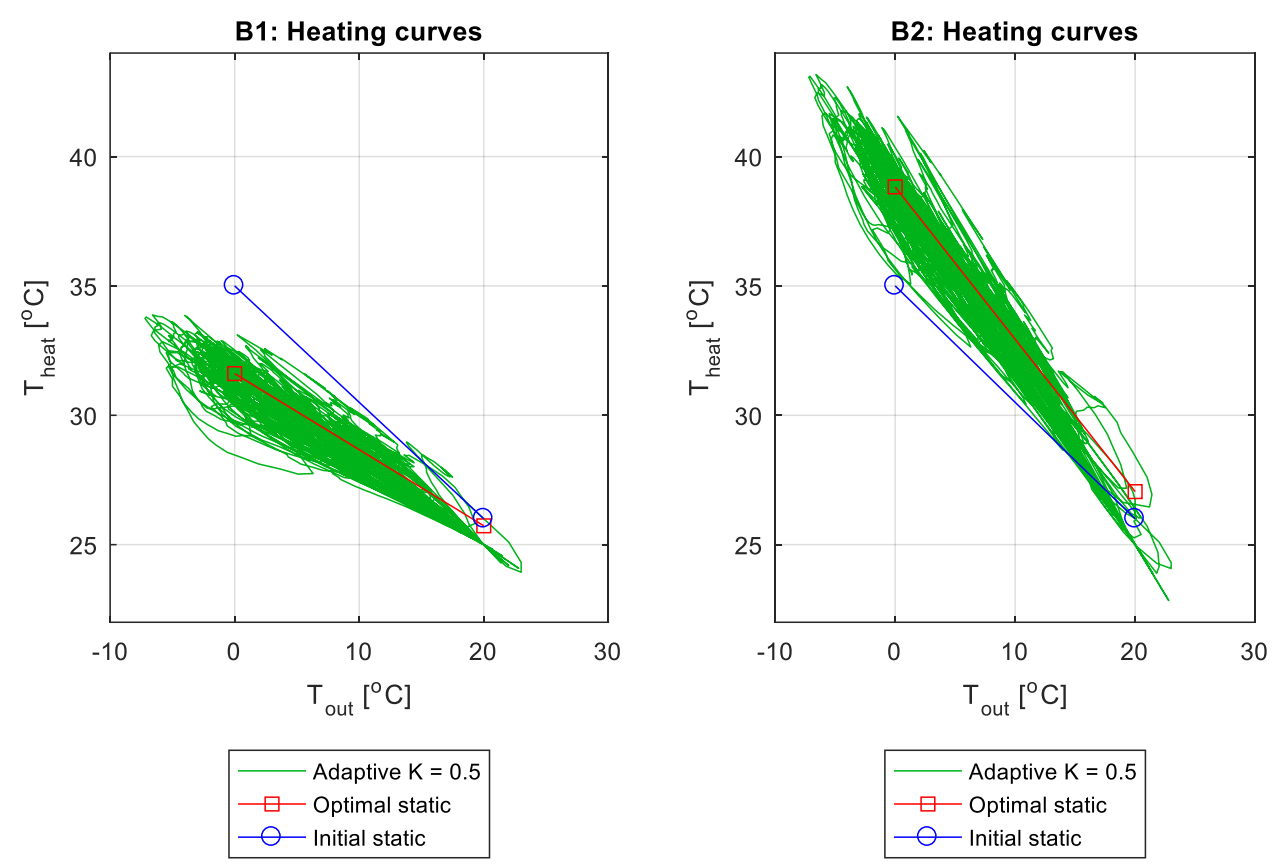

Figure 13: Graphical illustration of the adaptive heating curves $(K=0.5)$ for both buildings, with respect to the initial static and optimal static heating curves.

\section{Conclusions}

A method for the adaptive regulation of heating curves of weather-compensated heating by means of an air-to-water heat pump is proposed. The method involves parametrization of the heating curve by two reference points, defining the linear relationship between the heating temperature $T_{\text {heat }}$ and the outdoor temperature $T_{\text {out }}$. The aim of the performed research was to adaptively optimize the heating curve in order to achieve optimal thermal comfort in a building by minimizing the difference between the indoor temperature $T_{\text {in }}$ and the desired indoor temperature $T_{\text {in SET. }}$

The proposed method addresses the lack of proper error gradients for the adaptation of the heating curve by deriving approximate gradients from the instantaneous error $E$ by means of a weighting function $w$. The weighting function approximates error derivatives by distributing the instantaneous error to both reference points of the heating curve according to the proximity of the instantaneous outdoor temperature $T_{\text {out }}$ to each reference point ( $T_{\text {out REF1 }}$ and $T_{\text {out REF2 }}$ ).

Two adaptation strategies defining piecewise linear and hard-limiting weighting functions were investigated (Figure 6), and the results of the study show that although strategy S1 generally performs slightly better than strategy $\mathrm{S} 2$, the choice of adaptation strategy does not significantly affect the performance of the method. On the other hand, the adaptation constant $K$ which denotes the speed of adaptation, has a considerable effect on the adaptation results. It is shown that higher values of the adaptation constant, e.g. $K \approx 0.5$, result in rapid adaptive optimization which surpasses even the performance obtained by using optimal static heating curves. However, the choice of the adaptation constant is not critical, and a wide range of adaptation constants yields good long-term adaptation results.

Application of the method to two different buildings simulated in TRNSYS showed that the same arbitrary chosen initial heating curve will move toward the optimal settings that are different for each building. The proposed method therefore represents a simple and efficient way of relieving 
end users from having to manually adjust the heating curve reference points, and can be implemented in commercial heat pump regulators. Beside the gain in increased thermal comfort that results from good tracking of the desired indoor temperature, the method also provides energy savings due to heat pump operation at lower heating temperatures, which in turn increases the heat pump COP.

As a potential area for future work, the possibility of including other influential variables into the adaptation scheme will be investigated. Solar radiation, in particular, is known to have a considerable influence on the indoor temperature, so that methods which include solar radiation in the approximate adaptation strategy will be addressed, and possibly the effect of other variables.

\section{Funding}

This work was supported by ARRS - the Slovenian Research Agency, Research program P2-0241 "Synergetics of complex systems and processes", and was co-financed by the Republic of Slovenia and the European Union under the European Regional Development Fund.

\section{Nomenclature}

$\begin{array}{lll}\mathrm{ACH} & =\text { air changes per hour } & {[-]} \\ \mathrm{B} 1 & =\text { 1st building } & {[-]} \\ \mathrm{B} 2 & =\text { 2nd building } & {[-]} \\ \mathrm{COP} & =\text { coefficient of performance } & {[-]} \\ E & =\text { instantaneous error } & {\left[{ }^{\circ} \mathrm{C}\right]} \\ \mathrm{g} & =\text { total solar energy transmittance } & {[-]} \\ K & =\text { adaptation constant } & {[-]} \\ N & =\text { length of the observation period } & {[-]} \\ p & =\text { parameter of the linear function } & {[-]} \\ Q & =\text { heat gain } & {\left[\mathrm{W} / \mathrm{m}^{2}\right]} \\ \mathrm{R} & =\text { correlation coefficient } & {[-]} \\ \mathrm{RMSE} & =\text { Root Mean Square Error } & {\left[{ }^{\circ} \mathrm{C}\right]} \\ \mathrm{S} 1 & =\text { 1st adaptive strategy } & {[-]} \\ \mathrm{S} 2 & =\text { 2nd adaptive strategy } & {[-]} \\ \mathrm{Sf} & =\text { shading factor } & {[-]} \\ \mathrm{SR} & =\text { solar radiation } & {[\mathrm{W} / \mathrm{m} 2]} \\ T & =\text { temperature } & {\left[{ }^{\circ} \mathrm{C}\right]} \\ \mathrm{U} & =\text { thermal transmittance } & {\left[\mathrm{W} / \mathrm{m}^{2} \mathrm{~K}\right]} \\ w & =\text { weighting function } & {[-]}\end{array}$

\section{Subscripts}

$\begin{array}{ll}\text { B1 } & =1 \text { st building } \\ \text { B2 } & =2 \text { nd building } \\ \text { exterior wall } & =\text { exterior wall } \\ \text { floor } & =\text { floor } \\ \text { glazing } & =\text { glazing } \\ \text { heat } & =\text { water supply } \\ \text { heat REF1 } & =1 \text { st reference point } \\ \text { heat REF2 } & =2 \text { nd reference point } \\ \text { heat REF1 OPT } & =\text { optimal 1st reference point } \\ \text { heat REF2 OPT } & =\text { optimal 2nd reference point }\end{array}$




$\begin{array}{ll}\text { in } & =\text { indoor } \\ \text { in Set } & =\text { desired indoor } \\ \text { out } & =\text { outdoor } \\ \text { out REF1 } & =1 \text { st reference outdoor } \\ \text { out REF1 } & =2 \text { nd reference outdoor } \\ \text { out REFmean } & =\text { mean reference outdoor } \\ \text { roof } & =\text { roof }\end{array}$

\section{References}

Afram, Abdul, Farrokh Janabi-Sharifi, Alan S. Fung, and Kaamran Raahemifar. 2017. "Artificial Neural Network (ANN) Based Model Predictive Control (MPC) and Optimization of HVAC Systems: A State of the Art Review and Case Study of a Residential HVAC System.” Energy and Buildings 141: 96-113. doi:10.1016/j.enbuild.2017.02.012.

Al-Saadi, Saleh Nasser, and Zhiqiang Zhai. 2015. "A New Validated TRNSYS Module for Simulating Latent Heat Storage Walls.” Energy and Buildings 109: 274-290. doi:10.1016/j.enbuild.2015.10.013.

ARSO. 2017. "Weather Reference Year for Ljubljana, Slovenia." http://www.meteo.si/met/en/climate/tables/test_ref_year.

Balvedi, Bruna Faitão, Enedir Ghisi, and Roberto Lamberts. 2018. "A Review of Occupant Behaviour in Residential Buildings.” Energy and Buildings 174: 495-505. doi:10.1016/j.enbuild.2018.06.049.

Candanedo, José A, and Vahid R Dehkordi. 2014. "Simulation of Model-Based Predictive Control Applied to a Solar-Assisted Cold Climate Heat Pump System." In International High Performance Buildings Conference, 1-10. http://docs.lib.purdue.edu/ihpbc/149.

Carvalho, Anabela D., Pedro Moura, Gilberto C. Vaz, and Anibal T. De Almeida. 2015. "Ground Source Heat Pumps as High Efficient Solutions for Building Space Conditioning and for Integration in Smart Grids." Energy Conversion and Management 103: 991-1007. doi:10.1016/j.enconman.2015.07.032.

Chua, K. J., S. K. Chou, and W. M. Yang. 2010. "Advances in Heat Pump Systems: A Review." Applied Energy 87 (12): 3611-3624. doi:10.1016/j.apenergy.2010.06.014.

Crawley, Drury B., Jon W. Hand, Michael Kummert, and Brent T. Griffith. 2008. "Contrasting the Capabilities of Building Energy Performance Simulation Programs." Building and Environment 43: 661-673. doi:10.1016/j.buildenv.2006.10.027.

D’Oca, Simona, Tianzhen Hong, and Jared Langevin. 2018. "The Human Dimensions of Energy Use in Buildings: A Review." Renewable and Sustainable Energy Reviews 81: 731-742. doi:10.1016/j.rser.2017.08.019.

de Wilde, Pieter, and Wei Tian. 2010. "The Role of Adaptive Thermal Comfort in the Prediction of the Thermal Performance of a Modern Mixed-Mode Office Building in the UK under Climate Change.” Journal of Building Performance Simulation 3 (2): 87-101. doi:10.1080/19401490903486114.

"Directive 2010/31/EU of the European Parliament and of the Council of 19 May 2010 on the Energy Performance of Buildings (Recast)." 2010.

https://eur-lex.europa.eu/legal-content/EN/TXT/?uri=celex:32010L0031.

Fanger, P.O. 1970. Thermal Comfort: Analysis and Applications in Environmental Engineering. New York: McGraw-Hill Inc.

Fischer, David, and Hatef Madani. 2017. "On Heat Pumps in Smart Grids: A Review." Renewable and Sustainable Energy Reviews 70: 342-357. doi:10.1016/j.rser.2016.11.182. 
Hedegaard, Karsten, Brian Vad Mathiesen, Henrik Lund, and Per Heiselberg. 2012. "Wind Power Integration Using Individual Heat Pumps - Analysis of Different Heat Storage Options.” Energy 47: 284-293. doi:10.1016/j.energy.2012.09.030.

Huchtemann, K., and D. Müller. 2013. "Simulation Study on Supply Temperature Optimization in Domestic Heat Pump Systems.” Building and Environment 59: 327-335. doi:10.1016/j.buildenv.2012.08.030.

Ionesi, A., M. Jradi, J.E. Thorsen, and C.T. Veje. 2015. "Simulation of an Adaptive Heat Curve for Automatic Optimization of District Heating Installation." In 14th International Conference of IBPSA - Building Simulation 2015, 2117-2124.

"ISO 13790: 2008 Energy Performance of Buildings - Calculation of Energy Use for Space Heating and Cooling." 2008. In . International Organization for Standardization, Technical Committee : ISO/TC 163/SC 2 Calculation methods.

Kajgaard, Mikkel Urban, Jesper Mogensen, Anders Wittendorff, Attila Todor Veress, and Benjamin Biegel. 2013. "Model Predictive Control of Domestic Heat Pump." 2013 American Control Conference, 20132018. doi:10.1109/ACC.2013.6580131.

Kandler, Christian, Patrick Wimmer, and Johannes Honold. 2015. "Predictive Control and Regulation Strategies of Air-to-Water Heat Pumps.” Energy Procedia 78: 2088-2093. doi:10.1016/j.egypro.2015.11.239.

Klein, SA, WA Beckman, JW Mitchell, JA Duffie, NA Duffie, and TL Freeman. 2013. "TRNSYS 17: A Transient System Simulation Program."

Kreuder, Lukas, and Catalina Spataru. 2015. "Assessing Demand Response with Heat Pumps for Efficient Grid Operation in Smart Grids." Sustainable Cities and Society 19: 136-143. doi:10.1016/j.scs.2015.07.011.

Kronoterm d.o.o. 2017. Owner's Manual for Heat Pumps Water-water, Brine-water and Air-water, https://kronoterm.com/wp-content/uploads/2017/04/17-16-19-2972-02-Owner's-manual-HP_EN.pdf, Accessed date: 7 March 2019.

Kwak, Younghoon, and Jung Ho Huh. 2016. "Development of a Method of Real-Time Building Energy Simulation for Efficient Predictive Control." Energy Conversion and Management 113: 220-229. doi:10.1016/j.enconman.2016.01.060.

Laguna, Manuel., Marti, Rafael. 2002. The OptQuest callable library. S. Voss, D. Woodruff, eds. Optimization Software Class Libraries. Kluwer Academic Publishers, Boston, MA, 193-218.

Li, Xiwang, and Jin Wen. 2014. "Review of Building Energy Modeling for Control and Operation." Renewable and Sustainable Energy Reviews 37: 517-537. doi:10.1016/j.rser.2014.05.056.

Lindelöf, David, Hossein Afshari, Mohammad Alisafaee, Jayant Biswas, Miroslav Caban, Xavier Mocellin, and Jean Viaene. 2015. "Field Tests of an Adaptive, Model-Predictive Heating Controller for Residential Buildings." Energy and Buildings 99: 292-302. doi:10.1016/j.enbuild.2015.04.029.

Lu, Shilei, Yiqun Zhao, Kun Fang, Yiran Li, and Pengcheng Sun. 2017. "Establishment and Experimental Verification of TRNSYS Model for PCM Floor Coupled with Solar Water Heating System.” Energy and Buildings 140: 245-260. doi:10.1016/j.enbuild.2017.02.018.

Madani, Hatef, Joachim Claesson, and Per Lundqvist. 2011. "Capacity Control in Ground Source Heat Pump Systems: Part I: Modeling and Simulation.” International Journal of Refrigeration 34 (6): 1338-1347. doi:10.1016/j.ijrefrig.2011.05.007.

McLinden, Mark O., J. Steven Brown, Riccardo Brignoli, Andrei F. Kazakov, and Piotr A. Domanski. 2017. "Limited Options for Low-Global-Warming-Potential Refrigerants." Nature Communications 8: 1-9. doi:10.1038/ncomms14476. 
Meng, Fanlin, Kui Weng, Balsam Shallal, Xiangping Chen, and Monjur Mourshed. 2018. "Forecasting Algorithms and Optimization Strategies for Building Energy Management \&amp; Demand Response." Proceedings 2 (15): 1133. doi:10.3390/proceedings2151133.

Mohanraj, M., Ye Belyayev, S. Jayaraj, and A. Kaltayev. 2018. "Research and Developments on Solar Assisted Compression Heat Pump Systems - A Comprehensive Review (Part A: Modeling and Modifications)." Renewable and Sustainable Energy Reviews 83: 90-123. doi:10.1016/j.rser.2017.08.022.

Park, Chasik, Hoseong Lee, Yunho Hwang, and Reinhard Radermacher. 2015. "Recent Advances in Vapor Compression Cycle Technologies." International Journal of Refrigeration 60: 118-134. doi:10.1016/j.ijrefrig.2015.08.005.

Pedersen, Linda. 2007. "Use of Different Methodologies for Thermal Load and Energy Estimations in Buildings Including Meteorological and Sociological Input Parameters.” Renewable and Sustainable Energy Reviews 11 (5): 998-1007. doi:10.1016/j.rser.2005.08.005.

Poppi, Stefano, Nelson Sommerfeldt, Chris Bales, Hatef Madani, and Per Lundqvist. 2018. "Techno-Economic Review of Solar Heat Pump Systems for Residential Heating Applications." Renewable and Sustainable Energy Reviews 81 (May 2017): 22-32. doi:10.1016/j.rser.2017.07.041.

Potočnik, Primož, Boris Vidrih, Andrej Kitanovski, and Edvard Govekar. 2018. "Analysis and Optimization of Thermal Comfort in Residential Buildings by Means of a Weather-Controlled Air-to-Water Heat Pump." Building and Environment 140: 68-79. doi:10.1016/j.buildenv.2018.05.044.

Prívara, Samuel, Jiří Cigler, Zdeněk Váňa, Frauke Oldewurtel, Carina Sagerschnig, and Eva Žáčeková. 2013. "Building Modeling as a Crucial Part for Building Predictive Control." Energy and Buildings 56: 8-22. doi:10.1016/j.enbuild.2012.10.024.

Safa, Amir A., Alan S. Fung, and Rakesh Kumar. 2015. "Heating and Cooling Performance Characterisation of Ground Source Heat Pump System by Testing and TRNSYS Simulation.” Renewable Energy 83: 565575. doi:10.1016/j.renene.2015.05.008.

Sagia, Zoi, and Constantinos Rakopoulos. 2016. "Alternative Refrigerants for the Heat Pump of a Ground Source Heat Pump System.” Applied Thermal Engineering 100: 768-774. doi:10.1016/j.applthermaleng.2016.02.048.

Saloky, Tomas, and Jan Pitel. 2005. "Adaptive Control of Heating Process with Outdoor Temperature Compensation.” In ASR'2005 Seminar, Instruments and Control, 383-386. Ostrava.

Schmelas, Martin, Thomas Feldmann, and Elmar Bollin. 2017. "Savings through the Use of Adaptive Predictive Control of Thermo-Active Building Systems (TABS): A Case Study.” Applied Energy 199: 294-309. doi:10.1016/j.apenergy.2017.05.032.

Serale, Gianluca, Massimo Fiorentini, Alfonso Capozzoli, Daniele Bernardini, and Alberto Bemporad. 2018. "Model Predictive Control (MPC) for Enhancing Building and HVAC System Energy Efficiency: Problem Formulation, Applications and Opportunities." Energies 11 (3): 631. doi:10.3390/en11030631.

Smarra, Francesco, Achin Jain, Tullio De Rubeis, Dario Ambrosini, Alessandro D Innocenzo, and Rahul Mangharam. 2018. "Data-Driven Model Predictive Control Using Random Forests for Building Energy Optimization and Climate Control.” Applied Energy 226: 1252-1272. doi:10.1016/j.apenergy.2018.02.126.

Song, Mengjie, Shiming Deng, Chaobin Dang, Ning Mao, and Zhihua Wang. 2018. "Review on Improvement for Air Source Heat Pump Units during Frosting and Defrosting." Applied Energy 211: 1150-1170. doi:10.1016/j.apenergy.2017.12.022.

Thieblemont, Hélène, Fariborz Haghighat, Alain Moreau, and Gino Lacroix. 2018. "Control of Electrically Heated Floor for Building Load Management: A Simplified Self-Learning Predictive Control Approach.” 
Energy and Buildings 172: 442-458. doi:10.1016/j.enbuild.2018.04.042.

Thieblemont, Hélène, Fariborz Haghighat, Ryozo Ooka, and Alain Moreau. 2017. "Predictive Control Strategies Based on Weather Forecast in Buildings with Energy Storage System: A Review of the Stateof-the Art." Energy and Buildings 153: 485-500. doi:10.1016/j.enbuild.2017.08.010.

Ugray, Zsolt, Leon Lasdon, John Plummer, Fred Glover, James Kelly, and Rafael Marti. 2007. "Scatter Search and Local NLP Solvers: A Multistart Framework for Global Optimization.” INFORMS Journal on Computing 19 (3): 328-340. doi:10.1287/ijoc.1060.0175.

Vaillant. 2012. "VRC 470 Weather Compensator."

van Leeuwen, R P, I Gebhardt, J B de Wit, and G J M Smit. 2016. "A Predictive Model for Smart Control of a Domestic Heat Pump and Thermal Storage." Smartgreens: Proceedings of the 5th International Conference on Smart Cities and Green Ict Systems, 136-145. doi:10.5220/0005762201360145.

Willem, H., Y. Lin, and A. Lekov. 2017. "Review of Energy Efficiency and System Performance of Residential Heat Pump Water Heaters.” Energy and Buildings 143: 191-201. doi:10.1016/j.enbuild.2017.02.023.

William Goetzler, Robert Zogg, Jim Young, Caitlin Johnson. 2014. "Energy Savings Potential and RD \& D Opportunities for Non- Vapor-Compression HVAC." Energy Efficiency \& Renewable Energy, 3673. doi:10.2172/1220817.

Zhuang, Junhua, Yimin Chen, and Xiangguang Chen. 2018. "A New Simplified Modeling Method for Model Predictive Control in a Medium-Sized Commercial Building: A Case Study.” Building and Environment 127: 1-12. doi:10.1016/j.buildenv.2017.10.022.

Zygierewicz, Anna. 2016. Implementation of the Energy Efficiency Directive (2012/27/EU): Energy Efficiency Obligation Schemes. 